\title{
The cost of treatment and its related complications for men who receive surgery or radiation therapy for prostate cancer
}

Alaina Garbens ${ }^{1}$; Christopher J.D. Wallis ${ }^{1}$; Rano Matta ${ }^{1}$; Ronald Kodama ${ }^{1}$; Sender Herschorn ${ }^{1}$; Steven Narod ${ }^{3,4}$; and Robert K. Nam ${ }^{1}$

${ }^{1}$ Division of Urology, Sunnybrook Health Sciences Centre, University of Toronto, ON, Canada; ${ }^{2}$ Institute of Clinical Evaluative Sciences, Sunnybrook Research Institute, ON, Canada; ${ }^{3}$ Women's College Research Institute, Toronto, ON, Canada; ${ }^{4}$ Dalla Lana School of Public Health, University of Toronto, Toronto, ON, Canada

Funding: Funding for this research project was provided by The Ajmera Chair in Urologic Oncology.

Cite as: Can Urol Assoc J 2018 December 3; Epub ahead of print. http://dx.doi.org/10.5489/cuaj.5598

Published online December 3, 2018

$* * *$

\section{Abstract}

Introduction: We sought to examine the costs related to treatment and treatment-related complications for patients treated with surgery or radiation for localized prostate cancer.

Methods: We performed a population-based, retrospective cohort study of men who underwent open radical prostatectomy or radiation from 2004-2009 in Ontario, Canada. Costs, including initial treatment and inpatient hospitalization, emergency room visit, outpatient consultation, physician billings, and medication costs, were determined for five years following treatment using a validated costing algorithm. Multivariable negative binomial regression was used to assess the association between treatment modality and costs.

Results: A total of 28849 men underwent treatment for localized prostate cancer from 20042009. In the five years following treatment, men who underwent radiation ( $n=12675)$ had $21 \%$ higher total treatment and treatment-related costs than men who underwent surgery (\$16 716/person vs. \$13 213/person). Based on multivariable analysis, while men who underwent XRT had a lower relative cost in their first year after treatment (relative rate [RR] 0.97; 95\% confidence interval [CI] 0.94-1.0; $\mathrm{p}=0.025$ ), after year 2, annual costs were significantly higher in the radiation group compared to the surgery group (total cost for year 5, RR 1.44; 95\% CI 1.17-1.76; $\mathrm{p}<0.0001)$. Our results were similar when restricted to young, healthy men and to older men. 
Conclusions: Men who undergo radiation have significantly higher five-year total treatmentrelated costs compared to men who undergo open radical prostatectomy. While surgery was associated with slightly higher initial costs, radiotherapy had higher costs in subsequent years.

\section{Introduction}

The treatment options for patients diagnosed with localized prostate cancer include surgery or radiation therapy. ${ }^{1,2}$ Results from the largest study to date that randomized patients between surgery and radiation reported similar mortality rates. ${ }^{1}$ Thus, treatment choices for patients with localized disease continue to rely on patient and physician factors. ${ }^{3}$ The initial treatment can also have long-term consequences that result in complications that require additional treatments.

We previously described high rates of treatment-related complications (other than urinary incontinence and erectile dysfunction) among men in Ontario who were treated with surgery or radiation $^{4,5}$. Subsequent studies have confirmed our initial findings that treatment related complications are common to both treatments, with many patients experiencing a peak in complication rates at 2 years after treatment ${ }^{6,7}$. Furthermore, validation of these results using an American cohort found that treatment related complications frequently recur, with a mean number of complications of 2.6 per patient ${ }^{7}$. While such complications affect patient survivorship, they may also place a burden on the healthcare system.

To date, while the economic effect of incontinence and erectile dysfunction related to treatment of prostate cancer have been well studied, ${ }^{8-12}$ the costs associated with other treatment-related complications have not been examined. These costs, unlike those related to incontinence and erectile dysfunction, which are often incurred by the patient, are usually incurred by the health care system through government or third party payers. In order to better understand the costs of treatment of localized prostate cancer while considering treatment-related complications, we examined the absolute and relative 5-year health care utilization costs (consisting of treatment and treatment-related complications costs) for men undergoing surgery or radiation for localized prostate cancer among a large population-based cohort.

\section{Methods}

\section{Study subjects}

We performed a retrospective cohort study using a previously described cohort of men undergoing treatment for non-metastatic prostate cancer ${ }^{4}$. We excluded patient's who underwent treatment from January 12002 - December 312003 due to a paucity of available costing data. In brief, we included men over the age of 18 who had undergone either open radical prostatectomy or radiation therapy (external beam or brachytherapy) between January 12004 December 312009 in Ontario, Canada. We excluded patients who underwent minimally invasive surgery (either robotic or laparoscopic) as these procedures were not well established in Ontario 
during the study treatment period. Furthermore, while the use of robotic radical prostatectomy has expanded over the past decade, within Canada approximately $70 \%$ of radical prostatectomies are performed using open technique ${ }^{13}$. We excluded patients who underwent both radiation and surgery. After their initial treatment, patients were followed for 5 years or until death. Research ethics approval was obtained at the participating institute.

\section{Patient selection}

We identified patients diagnosed with prostate cancer using the Ontario Cancer Registry (OCR), a database of all newly diagnosed invasive cancers. We then linked treatment-related fee codes to identify patients who underwent treatment (surgery or radiation) within 1 year of diagnosis. The Ontario Health Insurance Plan (OHIP) is a government-run health insurance system that is used for physician fee reimbursement. For open radical prostatectomy, we used the fee code S651. For patients who underwent radiation therapy, planning codes (X310, X311, X312 and X313) and radiation follow up codes (A343, A340, A341, K013) were used for identification as previously described ${ }^{4}$. To exclude patients who may have received radiation as palliative therapy, we excluded patients who were initially diagnosed with or who developed metastatic disease during the study period.

\section{Cost determinants}

We determined the total 5-year costs for treatment and treatment related complications for localized prostate cancer. We defined total costs as health care utilization costs due to: hospital admissions, same day surgeries, emergency department visits, visits to a provincially recognized cancer center (for treatment, consultation and/or follow up), drug prescriptions (as captured through the Ontario Drug Benefit (ODB) program) and physician billings as a result of a complication.

We accessed data on hospital admissions, same day surgeries, emergency department visits and cancer clinic visits by linking to the Canadian Institute for Health Information (CIHI) Discharge Abstract Database, the National Ambulatory Care Reporting System, the Ontario Drug Benefit (ODB) program database and OHIP physician records. In Year 1, costs of the initial treatment were included. Years $2-5$ included follow up as well as costs related to treatment related complications.

As we wanted to examine costs related to complications from treatment (including standard treatment follow up), we only included costs linked to specific OHIP fee codes. These fee codes included consultations, surgeries, and small procedures related to known urinary, rectal and anal complications from treatment. A complete list of included OHIP billing codes can be found in Supplementary Table 3. 


\section{Derivation of cost estimations}

Hospital inpatient admissions, same day surgery clinics, emergency department and cancer clinic visits

We examined patient-level healthcare utilization costs within 5 years after initial treatment for prostate cancer. The cost for each patient was determined using costing methods developed for healthcare administrative data ${ }^{14}$. This method of patient costing has been extensively validated and used for several diseases including chronic diseases, critical care, spinal cord injury and trauma $^{15-18}$. Costs are calculated using the CIHI resource intensity weight (RIW) value and multiplying it by cost-per weighted case (CPWC), which is averaged across the province ${ }^{14,19,20}$. These costs are calculated annually and do not include physician OHIP billings. All dollar figures are reported in 2015 Canadian dollars.

Ontario drug benefit program

Prescription medications and associated pharmacy costs covered by the Ontario Drug Benefit Program (ODB) for patients 65 years of age or older, or under specific circumstances. We included medications that were related to prostate cancer treatment and complications (See Supplementary Table 4).

\section{Statistical analysis}

Primary analysis

Starting from the date of their initial treatment, patients were considered at risk for complications. They were followed until death or the last date of follow up for the study (obtained from the Registered Persons Database). Year 1 included treatment-related costs. Costs were compared using absolute and relative costs. Patients with missing costing data were excluded from the analysis. Study was reported as per the Strengthening the Reporting of Observational Studies in Epidemiology (STROBE) guidelines ${ }^{21}$.

\section{Absolute costs}

Absolute costs of treatment and treatment-related complications were defined as all costs based on health care utilization for patients in each primary treatment group. Cumulative and annual costs were calculated for each treatment group.

Relative costs

In order to compare annual per patient complication costs between patients who had primary surgery or radiation, we performed a multivariate negative binomial regression accounting for the dependence of matched data, for each year after treatment. This gave us the relative cost of radiation treated patients compared to surgically treated patients (expressed as the relative rate). For example, a relative cost of 1.5 for radiation means that patients treated with radiation cost on average $50 \%$ more than patients treated with surgery. Covariates included in the model were patient age, comorbidity, patient location and year of treatment. 
To address differences in baseline characteristics between patients treated with surgery and those treated with radiotherapy, we performed propensity score matching. The propensity score was determined based on a logistic regression model accounting for the following independent variables: age, comorbidity score (ADG), year of treatment, income quintile. Patients were matched 1:1 using the greedy algorithm.

Statistical significance was set at $\mathrm{p}<0.05$ based on a two-tailed comparison. All statistical analyses were performed in SAS Version 9.4.

Sub-analyses

We performed sub analyses looking at two distinct populations to account for differences in health care resource use due to age and comorbidities. To minimize the effects of selection bias, we examined a subgroup of the youngest and healthiest patients (aged 55 to 65, and ADG $\leq 5$ ). Also, because the cost of prescription medication is covered by the government only for patients aged 65 years or more, we examined a subgroup of patients older than 65.

\section{Results}

Overall, 28,849 men underwent treatment for localized prostate cancer during the study period. Of these men, 16,174 underwent open radical prostatectomy and 12,675 underwent radiation therapy. Men in the surgery group were younger, from higher social economic status, and healthier than patients in the radiation group (Table 1).

\section{Absolute costs}

Total treatment-related complication costs over 5 years

The total 5-year per patient cost was $\$ 13,213$ for men who were treated with radical prostatectomy and \$16,716 for men treated with radiation therapy (difference \$3,503, 21\%). For patients who underwent surgery and radiation, $74 \%$ and $63 \%$ of their total costs were incurred within the first year respectively. Annual costs were higher for patients who received radiation therapy for all 5 years (Table 2).

Cost breakdown by category

When we examined the costs by individual category, the highest cost was the inpatient category for the surgery group (\$7,927/patient over 5 years), while outpatient cancer management costs were the highest for patients who received radiation (\$9,912/patient over 5 years, Table 3). After Year 1, inpatient costs, emergency department visit costs and Ontario Drug Benefit costs were higher in men who underwent radiation (Table 3).

\section{Relative costs}

Multivariate analysis

After controlling for patient age, comorbidities, patient location and year of treatment, patients who received radiation had a significantly lower total cost relative to those who underwent 
surgery in the first year after treatment $(R R=0.82,95 \%$ CI 0.8-0.84, $\mathrm{p}<0.0001$, Table 4). Total costs for patients who received radiation were significantly higher from Year 2 onwards (Table 4).

When we restricted the study to patients who are young and healthy (aged between 55 65 years, $\mathrm{ADG} \leq 5$ ), and to patients aged $>65$ years, we found no change in the effect direction (Table 4).

Propensity matched multivariate analysis

In our propensity matched analysis, the results were similar. In the first year after treatment, the total costs among patients who received radiation were significantly lower than those who received surgery $(R R=0.97,95 \%$ CI 0.94-1.0, $\mathrm{p}=0.025)$. In Years $3-5$, the total costs among patients who received radiation were significantly higher than those who received surgery $(<0.05$ for all, Table 5). Inpatient visits, same day surgeries and emergency department visit costs were significantly lower in men treated with radiation in Year 1 ( $\mathrm{p}<0.0001$ for all). In Years 2 to 5, these costs became significantly higher in the radiation group ( $\mathrm{p}<0.0001$ for all). Ontario Drug Benefit costs were higher for all years in the radiation group relative to the surgery group (Table 5). By Year 5, outpatient cancer management costs were significantly lower in men who received radiation compared to surgery $(\mathrm{R} R=0.78(0.67-0.9, \mathrm{p}<0.002)$.

\section{Discussion}

In this population-based analysis, men who underwent open radical prostatectomy had $21 \%$ lower treatment-related health care expenditures over 5 years, compared with men who underwent radiation treatment for the treatment of localized prostate cancer. By the fifth year after treatment, men who underwent radiation cost almost twice as much per person annually (\$1,450/patient vs. \$800/patient), compared to men who underwent surgery. These differences in costs persisted among young, healthy men and among older men.

To our knowledge, this is the first analysis to compare costs between treatments for prostate cancer, while accounting for treatment related complications. Currently, the literature on treatment costs for localized prostate cancer treatment is limited, consisting mainly of decision analytic models. Gordon et al. determined the costs of prostate cancer treatment using a Markov model and demonstrated that surgery had a lower cost compared to radiation ${ }^{22}$. Cooperberg et al. determined that all forms of radiotherapy were associated with higher lifetime costs compared with any surgical approach ${ }^{11}$. Dorth et al. compared radiation therapy plus androgen deprivation therapy (ADT) to surgery plus radiation and found improved quality adjusted life expectancy but higher costs in the radiation group ${ }^{23}$. While helpful, these models did not include treatment related complication costs. Other cost effectiveness studies did not differentiate between treatment type in their models ${ }^{9,24,25}$.

Perlroth et al. found that the mean medical expenditures following the diagnosis of localized prostate cancer were \$96,300 USD for intensity-modulated radiation therapy, \$67,700 for brachytherapy and $\$ 49,800$ for radical prostatectomy ${ }^{26}$. These differences persisted when the 
authors accounted for age and comorbidities. The authors concluded that U.S health expenditures could be reduced by up to $\$ 14.5$ billion by shifting patients away from radiation therapy ${ }^{26}$.

Costs were highest in the first year of treatment regardless of treatment modality (surgery $\$ 9,739.70 /$ per person, radiation $\$ 10,606.49 /$ per person). First year costs comprised $74 \%$ of total costs for patients treated with surgery and $63 \%$ of total costs for those treated with radiotherapy. This is to be expected as our first year costs included the initial cost of treatment. For patients treated with radical prostatectomy, inpatient costs drove a significant proportion of overall costs in the first year, but a relatively small amount in subsequent years (less than $\$ 450$ per person annually).

Outpatient cancer management costs accounted for the vast majority of costs in the first year among the radiation group (\$8,987/per person) due to the frequent cancer clinic visits for radiation treatment planning and delivery. However, cancer clinic visit costs and OHIP billings from radiation oncologists sharply decreased after Year 1 (see Supplementary Table 1 and Table 2). In contrast, cancer clinic visits from men who underwent surgery had a more gradual decrease, and OHIP physician billings from urologists remained constant throughout the 5 years.

In contrast to the first year where costs are driven by the initial treatment, costs in subsequent years were driven by treatment-related complications. While patients who undergo surgery tend to experience most complications either immediately after surgery or within the first 2 years after treatment ${ }^{7}$, many radiation associated complications, including radiation cystitis/proctitis, fistulae and secondary malignancies ${ }^{27-29}$, have a delayed manifestation. This is consistent with our observation that costs for radiation were higher from Years 3 to 5.

An important strength of this analysis is the ability to determine costs at the population level using a previously validated costing method ${ }^{14-16,18}$. Also, our study used a large, population-based cohort, allowing for generalizations to a larger group of men with prostate cancer. Despite these strengths, our study has limitations. First, this analysis was performed in a single-payer, universal health insurance system. These results may not be generalizable to areas with alternative health care funding arrangements. Further, indirect costs were not considered. Our analysis did not consider robotic prostatectomy. While the robotic platform has been widely disseminated in the United States, the same has not happened in Canada, likely due to our publically funded healthcare system. As of 2016, only 4 provinces had robotic systems ${ }^{13}$. Based on a recent article by Childers et al., robotic surgery adds approximately $\$ 3,500$ per case ${ }^{30}$. It is unknown how robotic surgery would affect our costing analysis, as the literature is mixed as to whether the advantages of minimally invasive surgery (lower blood loss and decreased length of stay) outweigh the added cost of the robotic platform ${ }^{31}$.

In addition, we only examined patients who received either radiation or surgery. We did not look at patients who underwent combination therapy (salvage radiation or salvage prostatectomy). While we recognize that this subset of patients will have higher rates of complications and subsequent costs, the majority of men with localized prostate cancer will not have biochemical recurrence ${ }^{32-34}$. Comparative costs are poorly studied in men who receive 
salvage treatments and it is unknown how including these patients would effect our analysis. We also did not include costs related to infrastructure, including costs of equipment and maintenance and annual running costs of the operating room and radiation center. As OHIP only covers certain medications and patients older than 65, we could not capture all medications (ex. Phosphodiesterase type 5 inhibitors). Thus, these costs are likely underestimated.

\section{Conclusion}

We found that patients treated with radiotherapy for localized prostate cancer had significantly higher treatment-attributable costs in the 5 years following treatment, compared with those who underwent open radical prostatectomy. While surgery was associated with slightly higher initial costs, costs associated with radiation treatment were higher in subsequent years. 


\section{References}

1. Hamdy FC, Donovan JL, Lane JA, et al. 10-Year Outcomes after Monitoring, Surgery, or Radiotherapy for Localized Prostate Cancer. N Engl J Med. 2016;375(15):1415-1424.

2. Dahm P, Yeung LL, Chang SS, Cookson MS. A Critical Review of Clinical Practice Guidelines for the Management of Clinically Localized Prostate Cancer. The Journal of Urology. 2008;180(2):451-460.

3. Smith AB, Mancuso P, Sidhom M, et al. Prostatectomy versus radiotherapy for earlystage prostate cancer (PREPaRE) study: protocol for a mixed-methods study of treatment decision-making in men with localised prostate cancer. BMJ Open. 2017;7(11).

4. Nam RK, Cheung P, Herschorn S, et al. Incidence of complications other than urinary incontinence or erectile dysfunction after radical prostatectomy or radiotherapy for prostate cancer: a population-based cohort study. The Lancet Oncology. 2014;15(2):223231.

5. Wallis CJD, Herschorn S, Saskin R, et al. Complications After Radical Prostatectomy or Radiotherapy for Prostate Cancer: Results of a Population-based, Propensity Scorematched Analysis. Urology. 2015;85(3):621-628.

6. Wallis CJD, Mahar AL, Cheung P, et al. Hospitalizations to Manage Complications of Modern Prostate Cancer Treatment in Older Men. Urology. 2016;96:142-147.

7. Wallis CJD, Mahar A, Cheung P, et al. New Rates of Interventions to Manage Complications of Modern Prostate Cancer Treatment in Older Men. European Urology. 2016;69(5):933-941.

8. Siegel RL, Miller KD, Jemal A. Cancer statistics, 2016. CA: A Cancer Journal for Clinicians. 2016;66(1):7-30.

9. Krahn MD, Zagorski B, Laporte A, et al. Healthcare costs associated with prostate cancer: estimates from a population-based study. BJU International. 2010;105(3):338346.

10. Wilson LS, Tesoro R, Elkin EP, et al. Cumulative cost pattern comparison of prostate cancer treatments. Cancer. 2007;109(3):518-527.

11. Cooperberg MR, Ramakrishna NR, Duff SB, et al. Primary treatments for clinically localized prostate cancer: a comprehensive lifetime cost-utility analysis. BJU international. 2013;111(3):437-450.

12. Fradet Y, Klotz L, Trachtenberg J, Zlotta A. The burden of prostate cancer in Canada. Canadian Urological Association Journal. 2009;3(3 Suppl 2):S92-S100.

13. Health Quality O. Robotic Surgical System for Radical Prostatectomy: A Health Technology Assessment. Ont Health Technol Assess Ser. 2017;17(11):1-172.

14. Wodchis WP BK, Nikitovic M, McKillop I. Guidelines on PersonLevel Costing Using Administrative Databases in Ontario. Working Paper Series. Vol 1. Toronto: Health System Performance Research Network; 2013.

15. Munce SE, Wodchis WP, Guilcher SJ, et al. Direct costs of adult traumatic spinal cord injury in Ontario. Spinal Cord. 2013;51(1):64-69.

16. Wodchis WP, Austin PC, Henry DA. A 3-year study of high-cost users of health care. CMAJ : Canadian Medical Association Journal. 2016;188(3):182-188. 
17. Chaudhuri D, Tanuseputro P, Herritt B, D’Egidio G, Chalifoux M, Kyeremanteng K. Critical care at the end of life: a population-level cohort study of cost and outcomes. Critical Care. 2017;21:124.

18. Pincus D, Wasserstein D, Nathens AB, Bai YQ, Redelmeier DA, Wodchis WP. Direct medical costs of motorcycle crashes in Ontario. Canadian Medical Association Journal. 2017;189(46):E1410.

19. Chen A, Bushmeneva K, Zagorski B, Colantonio A, Parsons D, Wodchis WP. Direct cost associated with acquired brain injury in Ontario. BMC Neurology. 2012;12:76-76.

20. Information CIfH. Patient Cost Estimator Methodological Notes and Glossary. 2013(MIS and Costing, Health Spending and Strategic Initiatives):11.

21. von Elm E, Altman DG, Egger M, et al. The Strengthening the Reporting of Observational Studies in Epidemiology (STROBE) statement: guidelines for reporting observational studies. Lancet. 2007;370(9596):1453-1457.

22. Gordon LG, Tuffaha HW, James R, et al. Estimating the healthcare costs of treating prostate cancer in Australia: A Markov modelling analysis. Urologic Oncology: Seminars and Original Investigations. 2017.

23. Dorth JA, Lee WR, Chino J, Abouassaly R, Ellis RJ, Myers ER. Cost-Effectiveness of Primary Radiation Therapy Versus Radical Prostatectomy for Intermediate- to High-Risk Prostate Cancer. International Journal of Radiation Oncology*Biology*Physics. 2018;100(2):383-390.

24. Murray DK, Karen EB, Brandon Z, et al. Health Care Costs for State Transition Models in Prostate Cancer. Medical Decision Making. 2013;34(3):366-378.

25. Stokes ME, Black L, Benedict A, Roehrborn CG, Albertsen P. Long-term medical-care costs related to prostate cancer: estimates from linked SEER-Medicare data. Prostate Cancer Prostatic Dis. 2010;13(3):278-284.

26. Perlroth DJ, Goldman DP, Garber AM. The potential impact of comparative effectiveness research on U.S. health care expenditures. Demography. 2010;47 Suppl:S173-190.

27. Bassett MR, Santiago-Lastra Y, Stoffel JT, et al. Urinary Diversion for Severe Urinary Adverse Events of Prostate Radiation: Results from a Multi-Institutional Study. The Journal of Urology. 2017;197(3, Part 1):744-750.

28. Nieder AM, Porter MP, Soloway MS. Radiation Therapy for Prostate Cancer Increases Subsequent Risk of Bladder and Rectal Cancer: A Population Based Cohort Study. The Journal of Urology. 2008;180(5):2005-2010.

29. Wallis CJD, Mahar AL, Choo R, et al. Second malignancies after radiotherapy for prostate cancer: systematic review and meta-analysis. BMJ : British Medical Journal. 2016;352:i851.

30. Childers CP, Maggard-Gibbons M. Estimation of the Acquisition and Operating Costs for Robotic Surgery. JAMA. 2018;320(8):835-836.

31. Schroeck FR, Jacobs BL, Bhayani SB, Nguyen PL, Penson D, Hu J. Cost of New Technologies in Prostate Cancer Treatment: Systematic Review of Costs and Cost Effectiveness of Robotic-assisted Laparoscopic Prostatectomy, Intensity-modulated Radiotherapy, and Proton Beam Therapy. Eur Urol. 2017;72(5):712-735. 
32. Pound CR, Partin AW, Eisenberger MA, Chan DW, Pearson JD, Walsh PC. Natural history of progression after PSA elevation following radical prostatectomy. JAMA. 1999;281(17):1591-1597.

33. Kestin LL, Vicini FA, Ziaja EL, Stromberg JS, Frazier RC, Martinez AA. Defining biochemical cure for prostate carcinoma patients treated with external beam radiation therapy. Cancer. 1999;86(8):1557-1566.

34. Wallis CJD, Cheung P, Herschorn S, et al. Complications following surgery with or without radiotherapy or radiotherapy alone for prostate cancer. $\mathrm{Br}$ J Cancer. 2015;112(6):977-982. 
Figures and Tables

\begin{tabular}{|c|c|c|c|c|}
\hline & Treatment type & & & \\
\hline Variable & $\begin{array}{c}\text { Radical } \\
\text { prostatectomy } \\
\text { n=16 } 174 \\
\end{array}$ & $\begin{array}{c}\text { Radiation } \\
\text { therapy } \\
\mathbf{n}=12675 \\
\end{array}$ & $\begin{array}{c}\text { Total } \\
\text { n=28 } 849\end{array}$ & $\mathbf{p}$ \\
\hline Age & & & & $<0.001$ \\
\hline$<55$ & 2489 (15.4\%) & $473(3.7 \%)$ & $2962(10.3 \%)$ & \\
\hline 55-59 & 3467 (21.4\%) & $974(7.7 \%)$ & $4441(15.4 \%)$ & \\
\hline $60-64$ & $4476(27.7 \%)$ & $1651(13.0 \%)$ & $6127(21.2 \%)$ & \\
\hline 65-69 & $4064(25.1 \%)$ & $2591(20.4 \%)$ & 6655 (23.1\%) & \\
\hline $70-74$ & 1527 (9.4\%) & 3688 (29.1\%) & $5215(18.1 \%)$ & \\
\hline $75+$ & $151(0.9 \%)$ & 3298 (26.0\%) & $3449(12.0 \%)$ & \\
\hline $\begin{array}{l}\text { Income } \\
\text { quintile }\end{array}$ & & & & $<0.001$ \\
\hline Missing & $43(0.3 \%)$ & $36(0.3 \%)$ & $79(0.3 \%)$ & \\
\hline 1 & $2102(13.0 \%)$ & $2004(15.8 \%)$ & $4106(14.2 \%)$ & \\
\hline 2 & $2822(17.4 \%)$ & 2504 (19.8\%) & $5326(18.5 \%)$ & \\
\hline 3 & 3, $22(19.3 \%)$ & $2506(19.8 \%)$ & $5628(19.5 \%)$ & \\
\hline 4 & $3701(22.9 \%)$ & $2606(20.6 \%)$ & $6307(21.9 \%)$ & \\
\hline 5 & $4384(27.1 \%)$ & 3019 (23.8\%) & $7403(25.7 \%)$ & \\
\hline Total ADG & - & & & $<0.001$ \\
\hline $0-3$ & $3823(23.6 \%)$ & $2615(20.6 \%)$ & $6438(22.3 \%)$ & \\
\hline $4-5$ & 5958 (36.8\%) & $4057(32.0 \%)$ & $\begin{array}{c}10015 \\
(34.7 \%)\end{array}$ & \\
\hline $6-7$ & $3918(24.2 \%)$ & $3210(25.3 \%)$ & $7128(24.7 \%)$ & \\
\hline $8+$ & 2475 (15.3\%) & $2793(22.0 \%)$ & $5268(18.3 \%)$ & \\
\hline $\begin{array}{l}\text { Treatment } \\
\text { year }\end{array}$ & & $V$ & & $<0.001$ \\
\hline 2004 & $1717(10.6 \%)$ & $1370(10.8 \%)$ & $3087(10.7 \%)$ & \\
\hline 2005 & $2617(16.2 \%)$ & 2054 (16.2\%) & $4671(16.2 \%)$ & \\
\hline 2006 & 3031 (18.7\%) & $2238(17.7 \%)$ & $5269(18.3 \%)$ & \\
\hline 2007 & $3081(19.0 \%)$ & 2436 (19.2\%) & $5517(19.1 \%)$ & \\
\hline 2008 & $2960(18.3 \%)$ & 2339 (18.5\%) & $5299(18.4 \%)$ & \\
\hline 2009 & 2768 (17.1\%) & 2238 (17.7\%) & $5006(17.4 \%)$ & \\
\hline
\end{tabular}




\begin{tabular}{|c|c|c|}
\hline $\begin{array}{l}\text { Year since } \\
\text { treatment }\end{array}$ & $\begin{array}{c}\text { Radical prostatectomy } \\
n=16174\end{array}$ & $\begin{array}{c}\begin{array}{c}\text { Radiation therapy } \\
\mathrm{n}=12675\end{array} \\
\end{array}$ \\
\hline 1 & $\$ 9739.70$ & $\$ 10606.49$ \\
\hline 2 & $\$ 1021.74$ & $\$ 1564.61$ \\
\hline 3 & $\$ 836.71$ & $\$ 1563.86$ \\
\hline 4 & $\$ 814.61$ & $\$ 1531.15$ \\
\hline 5 & $\$ 799.80$ & $\$ 1450.35$ \\
\hline Overall & $\$ 13212.56$ & $\$ 16716.47$ \\
\hline
\end{tabular}

*Total costs consist of inpatient hospitalizations, cancer clinic, same day surgery, Ontario Drug Benefit, emergency department visits costs, and OHIP billings. Costs are presented in 2015 Canadian dollars.

\begin{tabular}{|c|c|c|}
\hline Year post-treatment & Radical prostatectomy & Radiation therapy \\
\hline \multicolumn{3}{|c|}{ Inpatient hospitalization costs per person per year } \\
\hline 1 & $\$ 6527$ & $\$ 1071$ \\
\hline 2 & $\$ 272$ & $\$ 786$ \\
\hline 3 & $\$ 320$ & $\$ 972$ \\
\hline 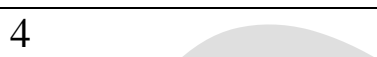 & $\$ 389$ & $\$ 1066$ \\
\hline 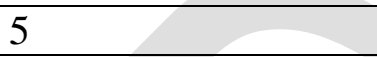 & $\$ 420$ & $\$ 998$ \\
\hline Total & $\$ 7927$ & $\$ 4892$ \\
\hline \multicolumn{3}{|c|}{ Same day surgery costs per person per year } \\
\hline 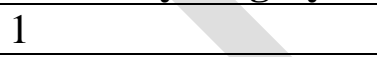 & $\$ 166$ & $\$ 83$ \\
\hline+2 & $\$ 77$ & $\$ 149$ \\
\hline+2 & $\$ 63$ & $\$ 113$ \\
\hline 4 & $\$ 62$ & $\$ 86$ \\
\hline 5 & $\sqrt{2}$ & $\$ 73$ \\
\hline Total & 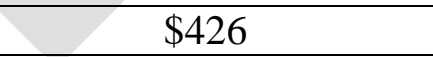 & $\$ 504$ \\
\hline \multicolumn{3}{|c|}{ Emergency department visit costs per person per year } \\
\hline 1 & $\$ 58$ & $\$ 44$ \\
\hline 2 & $\$ 14$ & $\$ 38$ \\
\hline 3 & $\$ 12$ & $\$ 29$ \\
\hline 4 & $\$ 14$ & $\$ 28$ \\
\hline 5 & $\$ 15$ & $\$ 28$ \\
\hline Total & $\$ 113$ & $\$ 167$ \\
\hline
\end{tabular}




\begin{tabular}{|l|c|c|}
\hline 1 & $\$ 2939$ & $\$ 8987$ \\
\hline 2 & $\$ 599$ & $\$ 290$ \\
\hline 3 & $\$ 383$ & $\$ 237$ \\
\hline 4 & $\$ 286$ & $\$ 206$ \\
\hline 5 & $\$ 237$ & $\$ 192$ \\
\hline Total & $\$ 4444$ & $\$ 9912$ \\
\hline \multicolumn{2}{|c|}{ Ontario Drug Benefit program cost per person per year } \\
\hline 1 & $\$ 50$ & $\$ 421$ \\
\hline 2 & $\$ 60$ & $\$ 302$ \\
\hline 3 & $\$ 58$ & $\$ 213$ \\
\hline 4 & $\$ 63$ & $\$ 145$ \\
\hline 5 & $\$ 71$ & $\$ 159$ \\
\hline Total & $\$ 301$ & $\$ 1240$ \\
\hline
\end{tabular}

${ }^{*}$ Costs include cancer clinic costs and OHIP physician billings related to treatment, followup, and treatment-related complications.

\begin{tabular}{|c|c|c|c|c|c|}
\hline Group & Year 1 & Year 2 & Year 3 & Year 4 & Year 5 \\
\hline \multicolumn{6}{|l|}{ Entire cohort } \\
\hline Surgery & 1.00 & 1.00 & 1.00 & 1.00 & 1.00 \\
\hline Radiation therapy & $\begin{array}{c}0.82 \\
(0.8-0.84) \\
\mathrm{p}<0.0001)\end{array}$ & $\begin{array}{c}1.01 \\
(0.95-1.07) \\
p=0.76\end{array}$ & $\begin{array}{c}1.17 \\
(1.1-1.25) \\
\mathrm{p}<0.0001\end{array}$ & $\begin{array}{c}1.29 \\
(1.2-1.37) \\
\mathrm{p}<0.0001\end{array}$ & $\begin{array}{c}1.30 \\
(1.21-1.39) \\
\mathrm{p}<0.0001\end{array}$ \\
\hline \multicolumn{6}{|c|}{ Men aged $55-65$ and $A D G \leq 5$} \\
\hline Surgery & 1.00 & 1.00 & 1.00 & 1.00 & 1.00 \\
\hline Radiation therapy & $\begin{array}{c}0.88 \\
(0.84-0.91) \\
\mathrm{p}<0.0001\end{array}$ & $\begin{array}{c}0.96 \\
(0.88-1.04) \\
p=0.31\end{array}$ & $\begin{array}{c}0.91 \\
(0.83-1.00) \\
p=0.04\end{array}$ & $\begin{array}{c}1.5 \\
(1.33-1.62) \\
\mathrm{p}<0.0001\end{array}$ & $\begin{array}{c}1.4 \\
(1.29-1.6) \\
\mathrm{p}<0.0001\end{array}$ \\
\hline \multicolumn{6}{|c|}{ Men aged $>65$ years } \\
\hline Surgery & 1.00 & 1.00 & 1.00 & 1.00 & 1.00 \\
\hline Radiation therapy & $\begin{array}{c}0.81 \\
(0.79-0.84) \\
\mathrm{p}<0.0001\end{array}$ & $\begin{array}{c}1.11 \\
(1.04-1.18) \\
\mathrm{p}<0.0001\end{array}$ & $\begin{array}{c}1.44 \\
(1.35-1.54) \\
\mathrm{p}<0.0001\end{array}$ & $\begin{array}{c}1.28 \\
(1.19-1.38) \\
\mathrm{p}<0.0001\end{array}$ & $\begin{array}{c}1.28 \\
(1.18-1.38) \\
\mathrm{p}<0.0001\end{array}$ \\
\hline
\end{tabular}

Data are relative rates (RR), (95\% confidence interval [CI]). Multivariate model also includes age, comorbidity (ADG case mix), year of treatment, and income. 


\begin{tabular}{|c|c|c|c|c|c|}
\hline Group & Year 1 & Year 2 & Year 3 & Year 4 & Year 5 \\
\hline \multicolumn{6}{|l|}{ Total cost } \\
\hline Surgery & 1.00 & 1.00 & 1.00 & 1.00 & 1.00 \\
\hline Radiation therapy & $\begin{array}{c}0.97 \\
(0.94-1.0) \\
\mathrm{p}=0.025\end{array}$ & $\begin{array}{c}1.12 \\
(0.98-1.29) \\
p=0.096 \\
\end{array}$ & $\begin{array}{c}1.28 \\
(1.07-1.54) \\
p=0.007 \\
\end{array}$ & $\begin{array}{c}1.26 \\
(1.03-1.54) \\
\mathrm{p}=0.025\end{array}$ & $\begin{array}{c}1.44 \\
(1.17-1.76) \\
\mathrm{p}<0.0001 \\
\end{array}$ \\
\hline \multicolumn{6}{|l|}{ Inpatient costs } \\
\hline Surgery & 1.00 & 1.00 & 1.00 & 1.00 & 1.00 \\
\hline Radiation therapy & $\begin{array}{c}0.11 \\
(0.1-0.13) \\
\mathrm{p}<0.0001\end{array}$ & $\begin{array}{c}2.23 \\
(1.66-2.99) \\
\mathrm{p}<0.0001 \\
\end{array}$ & $\begin{array}{c}1.97 \\
(1.44-2.7) \\
\mathrm{p}<0.0001\end{array}$ & $\begin{array}{c}1.76 \\
(1.25-2.46) \\
p=0.001\end{array}$ & $\begin{array}{c}1.98 \\
(1.43-2.74) \\
\mathrm{p}<0.0001\end{array}$ \\
\hline \multicolumn{6}{|l|}{ Same day surgery } \\
\hline Surgery & 1.00 & 1.00 & 1.00 & 1.00 & 1.00 \\
\hline Radiation therapy & $\begin{array}{c}0.57 \\
(0.51-0.64) \\
\mathrm{p}<0.0001 \\
\end{array}$ & $\begin{array}{c}1.49 \\
(1.31-1.71) \\
\mathrm{p}<0.0001 \\
\end{array}$ & $\begin{array}{c}1.44 \\
(1.25-1.67) \\
\mathrm{p}<0.0001 \\
\end{array}$ & $\begin{array}{c}1.17 \\
(0.99-1.38) \\
p=0.06\end{array}$ & $\begin{array}{c}1.02 \\
(0.85-1.23) \\
p=0.83\end{array}$ \\
\hline \multicolumn{6}{|c|}{ Emergency department visits } \\
\hline Surgery & 1.00 & 1.00 & 1.00 & 1.00 & 1.00 \\
\hline Radiation therapy & $\begin{array}{c}0.54 \\
(0.46-0.63) \\
\mathrm{p}<0.0001\end{array}$ & $\begin{array}{c}1.89 \\
(1.4-2.56) \\
\mathrm{p}<0.0001\end{array}$ & $\begin{array}{c}1.76 \\
(1.34-2.33) \\
\mathrm{p}<0.0001\end{array}$ & $\begin{array}{c}1.54 \\
(1.19-2.01) \\
p=0.001\end{array}$ & $\begin{array}{c}1.55 \\
(1.17-2.05) \\
p=0.003)\end{array}$ \\
\hline \multicolumn{6}{|c|}{ Cancer treatment and followup costs per person per year ${ }^{\S}$} \\
\hline Surgery & 1.00 & 1.00 & 1.00 & 1.00 & 1.00 \\
\hline Radiation therapy & $\begin{array}{c}2.8 \\
(2.7-2.89) \\
\mathrm{p}<0.0001 \\
\end{array}$ & $\begin{array}{c}0.43 \\
(0.39-0.48) \\
\mathrm{p}<0.0001 \\
\end{array}$ & $\begin{array}{c}0.58 \\
(0.51-0.65) \\
\mathrm{p}<0.0001 \\
\end{array}$ & $\begin{array}{c}0.63 \\
(0.56-0.72) \\
\mathrm{p}<0.0001 \\
\end{array}$ & $\begin{array}{c}0.78 \\
(0.67-0.9) \\
\mathrm{p}=0.002 \\
\end{array}$ \\
\hline \multicolumn{6}{|c|}{ Ontario drug benefit program } \\
\hline Surgery & 1.00 & 1.00 & 1.00 & 1.00 & 1.00 \\
\hline Radiation therapy & $\begin{array}{c}3.95 \\
(3.23-4.82) \\
p<0.0001\end{array}$ & $\begin{array}{c}2.33 \\
(1.9-2.87) \\
p<0.0001 \\
\end{array}$ & $\begin{array}{c}2.05 \\
(1.67-2.52) \\
p=0.001\end{array}$ & $\begin{array}{c}1.21 \\
(0.88-1.67) \\
p=0.24\end{array}$ & $\begin{array}{c}1.44 \\
(1.1-1.88) \\
\mathrm{p}=0.009\end{array}$ \\
\hline
\end{tabular}

Data are relative rates (RR), (95\% confidence interval [CI]. Patients are matched 1:1. Propensity score was calculated based on patient's age, income quintile, ADG and year of diagnosis.

${ }^{\S}$ Costs include cancer clinic visits costs and OHIP physician billings related to treatment, followup, and treatment-related complications. 


\begin{tabular}{|c|c|c|}
\hline \multicolumn{3}{|c|}{$\begin{array}{l}\text { Supplementary Table } 1 \text {. Annual 5-year per person cancer clinic visit } \\
\text { costs for men who were treated with surgery or radiation therapy } \\
\text { for localized prostate cancer }\end{array}$} \\
\hline Year post-treatment & $\begin{array}{c}\text { Radical } \\
\text { prostatectomy (\$) }\end{array}$ & $\begin{array}{l}\text { Radiation therapy } \\
\text { (\$) }\end{array}$ \\
\hline Year 1 & 982.77 & 7778.17 \\
\hline Year 2 & 384.36 & 41.08 \\
\hline Year 3 & 197.21 & 22.41 \\
\hline Year 4 & 123.82 & 24.25 \\
\hline Year 5 & 84.93 & 21.75 \\
\hline Total & 1773.09 & 7887.66 \\
\hline
\end{tabular}

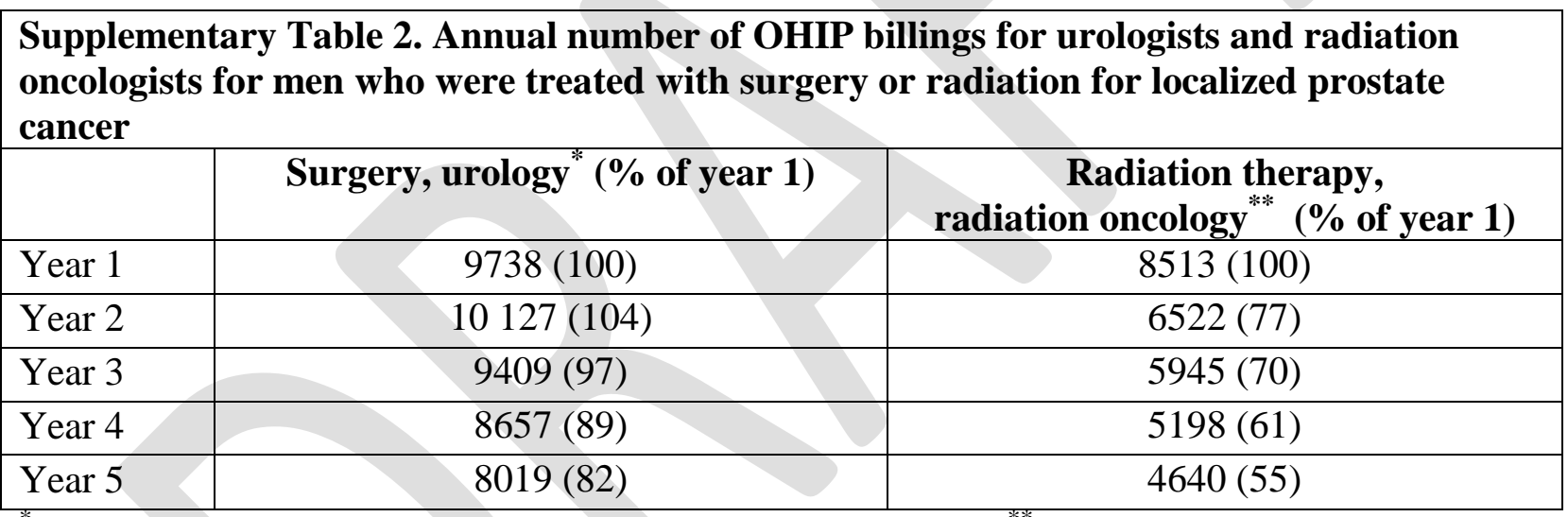

${ }^{*}$ Urology billings include OHIP fee codes A353, A354, A355. ${ }^{* *}$ Radiation oncology billings include OHIP fee codes A348, X313, A340, A343, A341. OHIP: Ontario Health Insurance Plan. 


\begin{tabular}{|c|c|}
\hline \multicolumn{2}{|c|}{$\begin{array}{l}\text { Supplementary Table } 3 \text {. List of Ontario Health Insurance Plan (OHIP) physician fee codes } \\
\text { that were included in determining treatment and treatment-related complication costs in } \\
\text { treatment for localized prostate cancer }\end{array}$} \\
\hline Fee code & Description of code \\
\hline A001 & Minor assessment - family practitioner \\
\hline A003 & General assessment - family practitioner \\
\hline A004 & General re-assessment - family practitioner \\
\hline A005 & Consultation - family medicine \\
\hline A008 & Mini assessment - family practitioner \\
\hline A015 & Consultation - anesthesia \\
\hline A033 & Specific assessment - general surgery \\
\hline A034 & Partial assessment - general surgery \\
\hline A035 & Consultation - general surgery \\
\hline A036 & Repeat consultation - general surgery \\
\hline A131 & Complex medical specific re-assessment - internal and occupational medicine \\
\hline A133 & Medical specific assessment - internal and occupational medicine \\
\hline A134 & Medical specific re-assessment - internal and occupational medicine \\
\hline A340 & Medical specific re-assessment - radiation oncology \\
\hline A341 & Complex medical specific re-assessment - radiation oncology \\
\hline A343 & Medical specific assessment - radiation oncology \\
\hline A345 & Consultation - radiation oncology \\
\hline A346 & Re-consultation - radiation oncology \\
\hline A348 & Partial assessment - radiation oncology \\
\hline A353 & Specific assessment - urology \\
\hline A354 & Partial assessment - urology \\
\hline A355 & Consultation - urology \\
\hline A356 & Re-consultation - urology \\
\hline A411 & Complex medical specific re-assessment - gastroenterology \\
\hline A413 & Medical specific assessment - gastroenterology \\
\hline A414 & Medical specific re-assessment - gastroenterology \\
\hline A415 & Consultation - gastroenterology \\
\hline A418 & Partial assessment - gastroenterology \\
\hline A441 & Complex medical specific re-assessment - medical oncology \\
\hline A443 & Medical specific assessment - medical oncology \\
\hline A444 & Medical specific re-assessment - medical oncology \\
\hline A445 & Consultation - medical oncology \\
\hline A448 & Partial assessment - medical oncology \\
\hline A473 & Medical specific assessment - internal medicine \\
\hline A474 & Medical specific re-assessment - internal medicine \\
\hline
\end{tabular}




\begin{tabular}{|c|c|}
\hline A585 & Diagnostic consultation - pathology \\
\hline A745 & Limited consultation - radiation oncology \\
\hline A771 & Pronouncement of death \\
\hline A888 & 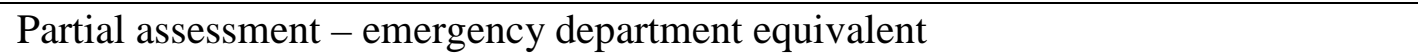 \\
\hline A935 & Preamble - special surgical consultation \\
\hline C012 & Subsequent hospital visit up to 5 weeks - anesthesia \\
\hline C013 & Special assessment - anesthesia \\
\hline C018 & Concurrent hospital care - anesthesia \\
\hline C032 & Subsequent hospital visit up to five weeks - general surgery \\
\hline C038 & Concurrent hospital care - general surgery \\
\hline C101 & Intensive care unit premiums \\
\hline C122 & Most responsible physician \\
\hline C123 & Most responsible physician \\
\hline C124 & Day of discharge visit - most responsible physician \\
\hline C342 & Subsequent hospital visit - radiation oncology \\
\hline C352 & Subsequent hospital visit - urology \\
\hline C353 & Specific hospital assessment - urology \\
\hline C354 & Specific hospital re-assessment - urology \\
\hline C355 & Hospital consultation - urology \\
\hline C358 & Concurrent hospital care - urology \\
\hline C412 & Subsequent hospital visits - gastroenterology \\
\hline C418 & Concurrent care \\
\hline C990 & Special hospital inpatient visit \\
\hline C994 & Special hospital inpatient visit \\
\hline C995 & Special hospital inpatient visit \\
\hline E022 & Anaesthesia extra units \\
\hline E023 & Anaesthesia basic units \\
\hline E082 & Admission assessment by most responsible physician \\
\hline E083 & $\begin{array}{l}\text { Subsequent visit by the most responsible physician, to subsequent visit, c122, c123, } \\
\text { c124, c142, c143, c882 or c982 }\end{array}$ \\
\hline E702 & Oesophagoscopy with multiple biopsies \\
\hline E705 & Digestive system - intestinal endoscopy into terminal ileum, add on \\
\hline E717 & Colonoscopy - biopsy/coagulation of lesion \\
\hline E720 & Colonoscopy - excision of polyp \\
\hline E740 & Intestine endoscopy - sigmoid to splenic flexure, add on \\
\hline E741 & Intestine endoscopy - sigmoid to hepatic flexure, add on \\
\hline E746 & Sigmoidoscopy - performed outside of hospital \\
\hline E747 & Intestine endoscopy - sigmoid.to caecum add to z512/z555 \\
\hline E749 & Digestive system - when z512,555,580 performed outside of hospital, add on \\
\hline E787 & Cystoscopy with resection or incision of bladder neck, male, add on \\
\hline
\end{tabular}




\begin{tabular}{|c|c|}
\hline E797 & Management of upper or lower gastrointestinal bleeding by any technique \\
\hline G009 & Urinalysis routine \\
\hline G010 & Urinalysis \\
\hline G192 & Video fluoroscopic multichannel urodynamic assessment \\
\hline G224 & Nerve block \\
\hline G247 & Nerve block - hospital visits \\
\hline G339 & Chemotherapy - single-agent intravenous chemotherapy \\
\hline G379 & Adult intravenous \\
\hline G381 & Intravenous chemotherapy \\
\hline G382 & Supervision of chemotherapy by telephone, monthly \\
\hline G395 & Critical care first $1 / 4$ hour \\
\hline G401 & Critical intensive care \\
\hline G475 & Cystometrogram \& or voiding pressure \\
\hline G511 & Telephone management of palliative care at home \\
\hline G512 & Palliative care case management fee \\
\hline G900 & Residual urine measurement \\
\hline H065 & Emergency physician consult \\
\hline H101 & Minor assessment - emergency \\
\hline H102 & Comprehensive assessment and care - emergency medicine \\
\hline H103 & Multiple systems assessment - emergency medicine \\
\hline H104 & Re-assessment - emergency medicine \\
\hline H105 & In-patient interim admission orders \\
\hline H122 & Comprehensive assessment and care - emergency medicine (00:00h-08:00h) \\
\hline H122 & Comprehensive assessment and care - emergency medicine (00:00h-08:00h) \\
\hline H123 & Multiple systems assessment - emergency medicine (00:00h-08:00h) \\
\hline H124 & Re-assessment - emergency medicine (00:00h-08:00h) \\
\hline H131 & Minor assessment - emergency (18:00h-24:00h) \\
\hline H132 & Comprehensive assessment and care - emergency medicine (18:00h-24:00h) \\
\hline H133 & Multiple systems assessment - emergency medicine (18:00h-24:00h) \\
\hline H134 & Re-assessment - emergency medicine (18:00h-24:00h) \\
\hline H151 & Minor assessment - emergency (Holidays) \\
\hline H152 & Comprehensive assessment and care - emergency medicine (holidays) \\
\hline H153 & Multiple systems assessment - emergency medicine (holidays) \\
\hline H154 & Re-assessment - emergency medicine (holidays) \\
\hline J028 & Diagnostic radiology - urethrocystogram \\
\hline J128 & Diagnostic ultrasound - abdominal scan - limited study \\
\hline J138 & Intracavitary ultrasound (transrectal) \\
\hline J149 & Ultrasound guidance of biopsy, aspiration, amniocentesis or drainage procedures \\
\hline J162 & Ultrasound - pelvis complete \\
\hline J163 & Diagnostic ultrasound - pelvis, limited study other than pregnancy \\
\hline
\end{tabular}




\begin{tabular}{|l|l|}
\hline K002 & Interviews-relatives on behalf of patient per 1/2 hour \\
\hline K005 & Individual care per 1/2 hour \\
\hline K013 & Counselling one or more people-per 1/2hr. \\
\hline K015 & Counselling relatives on behalf of patient \\
\hline K070 & Home care application \\
\hline K990 & Special visits emergency department premiums \\
\hline K991 & Special visits emergency department premiums \\
\hline K994 & Special visits emergency department premiums \\
\hline K995 & Special visits emergency department premiums \\
\hline L634 & Urine microbiology and culture \\
\hline Q133 & Colorectal screening tracking code \\
\hline Q142 & Colorectal exclusion \\
\hline Q150 & Fecal occult blood distribution and counselling fee \\
\hline Q200 & Per patient rostering fee \\
\hline S323 & Herniotomy \\
\hline S519 & Surgical repair of bladder neck \\
\hline S532 & Transurethral visual urethrotomy \\
\hline S539 & Insertion of artificial urinary sphincter \\
\hline S548 & Urethral sling \\
\hline S573 & Circumcision \\
\hline S636 & Vesiculectomy \\
\hline S640 & Stereotactic prostate brachytherapy \\
\hline S651 & Prostatectomy/vasectomy-retropubic radical \\
\hline S652 & Pelvic lymphadenectomy for prostate cancer \\
\hline S653 & Laparoscopic radical prostatectomy \\
\hline S655 & Transurethral resection of prostate \\
\hline X310 & Radiation treatment planning level 1 \\
\hline X311 & Radiation treatment planning level 2 \\
\hline X312 & Radiation treatment planning level 3 \\
\hline X313 & Radiation treatment planning level 4 \\
\hline Z399 & Elective oesophagoscopy \\
\hline Z400 & Endoscopy for active bleeding \\
\hline Z535 & Sigmoidoscopy with or without anoscopy \\
\hline Z543 & Anoscopy \\
\hline Z555 & Colonoscopy into descending colon \\
\hline Z570 & Colonoscopy - excision/fulguration of polyps \\
\hline Z571 & Colonoscopy - excision/fulguration of polyps \\
\hline Z580 & Sigmoidoscopy \\
\hline Z602 & Bladder - catheterization in office \\
\hline Z606 & Cystoscopy \\
\hline
\end{tabular}




\begin{tabular}{|l|l|}
\hline Z607 & Cystoscopy - repeat within 30 days \\
\hline Z608 & Manual catheter declotting and irrigation of bladder \\
\hline Z611 & Bladder - catheterization in hospital \\
\hline Z615 & Filiform \& follower urethral dilatation \\
\hline Z619 & Dilation of urethral stricture under general anaesthetic, male \\
\hline Z621 & Dilation of urethral stricture under local anaesthetic, male \\
\hline Z628 & Cystoscopy and diagnostic ureteroscopy \\
\hline Z700 & Intracorporeal injection for impotence \\
\hline Z712 & Prostate needle biopsy \\
\hline
\end{tabular}

\begin{tabular}{|c|c|c|}
\hline \multicolumn{3}{|c|}{$\begin{array}{l}\text { Supplementary Table } 4 \text {. List of medications that were included in } \\
\text { determining treatment and treatment-related complication costs in } \\
\text { treatment for localized prostate cancer }\end{array}$} \\
\hline Drug category & Name & Drug ID number \\
\hline Alpha blocker & Tamsulosin HCL & 02362406 \\
\hline Alpha blocker & Tamsulosin HCL & 02270102 \\
\hline Alpha blocker & Tamsulosin HCL & 09857334 \\
\hline Alpha blocker & Tamsulosin HCL & 02340208 \\
\hline Alpha blocker & Tamsulosin HCL & 02368242 \\
\hline Alpha blocker & Tamsulosin HCL & 02238123 \\
\hline Alpha blocker & Tamsulosin HCL & 02298570 \\
\hline Alpha blocker & Tamsulosin HCL & 02281392 \\
\hline Alpha blocker & Tamsulosin HCL & 02294265 \\
\hline Alpha blocker & Tamsulosin HCL & 02319217 \\
\hline Alpha blocker & Sildosin & 02361663 \\
\hline Alpha blocker & Sildosin & 02361671 \\
\hline Alpha blocker & Alfuzosin & 02245565 \\
\hline Alpha blocker & Doxazosin & 02240589 \\
\hline Alpha blocker & Doxazosin & 02240590 \\
\hline Alpha blocker & Doxazosin & 02240588 \\
\hline Alpha blocker & Doxazosin & 02242730 \\
\hline Alpha blocker & Doxazosin & 02242729 \\
\hline Alpha blocker & Doxazosin & 02242728 \\
\hline Alpha blocker & Doxazosin & 02244529 \\
\hline Alpha blocker & Doxazosin & 02244528 \\
\hline Alpha blocker & Doxazosin & 02244527 \\
\hline Alpha blocker & Terazosin & 02234504 \\
\hline Alpha blocker & Terazosin & 02234505 \\
\hline
\end{tabular}




\begin{tabular}{|c|c|c|}
\hline Alpha blocker & Terazosin & 02234503 \\
\hline Alpha blocker & Terazosin & 02234502 \\
\hline Alpha blocker & Terazosin & 00818658 \\
\hline Alpha blocker & Terazosin & 00818666 \\
\hline Alpha blocker & Terazosin & 00818682 \\
\hline Alpha blocker & Terazosin & 00818674 \\
\hline Alpha blocker & Terazosin & 02243520 \\
\hline Alpha blocker & Terazosin & 02243519 \\
\hline Alpha blocker & Terazosin & 02243518 \\
\hline Alpha blocker & Terazosin & 02243521 \\
\hline Alpha blocker & Terazosin & 02230806 \\
\hline Alpha blocker & Terazosin & 02230805 \\
\hline Alpha blocker & Terazosin & 02230808 \\
\hline Alpha blocker & Terazosin & 02230807 \\
\hline 5ARI & finasteride & 02365383 \\
\hline 5ARI & finasteride & 02405814 \\
\hline 5ARI & finasteride & $\underline{02428148}$ \\
\hline 5ARI & finasteride & 02354462 \\
\hline 5ARI & finasteride & 02355043 \\
\hline 5ARI & finasteride & 02357224 \\
\hline 5ARI & finasteride & 02389878 \\
\hline 5ARI & finasteride & 02356058 \\
\hline 5ARI & finasteride & 02392631 \\
\hline 5ARI & finasteride & 02348500 \\
\hline 5ARI & finasteride & 02320169 \\
\hline 5ARI & finasteride & 02310112 \\
\hline 5ARI & finasteride & 02238213 \\
\hline 5ARI & finasteride & 09857529 \\
\hline 5ARI & finasteride & 02010909 \\
\hline 5ARI & finasteride & 02371820 \\
\hline 5ARI & finasteride & 02306905 \\
\hline 5ARI & finasteride & 02322579 \\
\hline 5ARI & finasteride & 02339471 \\
\hline 5ARI & finasteride & 02428741 \\
\hline 5ARI & Dutasteride & 02412691 \\
\hline 5ARI & Dutasteride & 02404206 \\
\hline 5ARI & Dutasteride & 02247813 \\
\hline 5ARI & Dutasteride & 02416298 \\
\hline 5ARI & Dutasteride & 02428873 \\
\hline 5ARI & Dutasteride & 02393220 \\
\hline
\end{tabular}




\begin{tabular}{|c|c|c|}
\hline 5ARI & Dutasteride & 02424444 \\
\hline 5ARI & Dutasteride & 02408287 \\
\hline PD5 inhibitors & Sildenafil & 02239767 \\
\hline PD5 inhibitors & Sildenafil & 02239766 \\
\hline PD5 inhibitors & Sildenafil & 02239768 \\
\hline PD5 inhibitors & Tadalafil $20 \mathrm{mg}$ & 02421933 \\
\hline PD5 inhibitors & Tadalfil $10 \mathrm{mg}$ & 02248088 \\
\hline PD5 inhibitors & Tadalafil 5mg & 02296896 \\
\hline PD5 inhibitors & Tadalafil $2.5 \mathrm{mg}$ & 02296888 \\
\hline PD5 inhibitors & Vardenafil 10 mg & 02250470 \\
\hline PD5 inhibitors & Vardenafil $20 \mathrm{mg}$ & 02250489 \\
\hline PD5 inhibitors & Vardenafil 5 mg & 02250462 \\
\hline Beta 3 agonist & mirabegron 50 mg & 02402882 \\
\hline Beta 3 agonist & Mirabegron 25 mg & 02402874 \\
\hline Anti-muscarinic & Darifenacin & 02273225 \\
\hline Anti-muscarinic & Darifenacin & 02273217 \\
\hline Anti-muscarinic & Fesoterodine & 02380048 \\
\hline Anti-muscarinic & Fesoterodine & 02380021 \\
\hline Anti-muscarinic & Oxybutynin & 01924753 \\
\hline Anti-muscarinic & Oxybutynin & 02223376 \\
\hline Anti-muscarinic & Oxybutynin & 02163543 \\
\hline Anti-muscarinic & Oxybutynin & 01924761 \\
\hline Anti-muscarinic & Oxybutynin & 02230800 \\
\hline Anti-muscarinic & Oxybutynin & 02230394 \\
\hline Anti-muscarinic & Oxybutynin & 02240550 \\
\hline Anti-muscarinic & $\begin{array}{c}\text { Oxybutynin } 10 \% \text { topical } \\
\text { gel }\end{array}$ & 02366150 \\
\hline Anti-muscarinic & Solifenacin & 02422247 \\
\hline Anti-muscarinic & Solifenacin & 02422239 \\
\hline Anti-muscarinic & Solifenacin & 02424339 \\
\hline Anti-muscarinic & Solifenacin & 02424347 \\
\hline Anti-muscarinic & Solifenacin & 02417731 \\
\hline Anti-muscarinic & Solifenacin & 02417723 \\
\hline Anti-muscarinic & Solifenacin & 02437988 \\
\hline Anti-muscarinic & Solifenacin & 02437996 \\
\hline Anti-muscarinic & Solifenacin & 02399040 \\
\hline Anti-muscarinic & Solifenacin & 02399032 \\
\hline Anti-muscarinic & Solifenacin & 02397919 \\
\hline Anti-muscarinic & Solifenacin & 02397900 \\
\hline Anti-muscarinic & Solifenacin & 02277263 \\
\hline
\end{tabular}




\begin{tabular}{|c|c|c|}
\hline Anti-muscarinic & Solifenacin & 02277271 \\
\hline Anti-muscarinic & Tolterodine & 02244612 \\
\hline Anti-muscarinic & Tolterodine & 02244613 \\
\hline Anti-muscarinic & Tolterodine & 02404184 \\
\hline Anti-muscarinic & Tolterodine & 02404192 \\
\hline Anti-muscarinic & Tolterodine & 02413159 \\
\hline Anti-muscarinic & Tolterodine & 02413140 \\
\hline Anti-muscarinic & Tolterodine & 02412195 \\
\hline Anti-muscarinic & Tolterodine & 02412209 \\
\hline Anti-muscarinic & Tolterodine & 02369680 \\
\hline Anti-muscarinic & Tolterodine & 02369699 \\
\hline Anti-muscarinic & Tolterodine & 02239065 \\
\hline Anti-muscarinic & Tolterodine & 02239064 \\
\hline Anti-muscarinic & Tolterodine & 02423308 \\
\hline Anti-muscarinic & Tolterodine & 02423316 \\
\hline Anti-muscarinic & Tolterodine & 02299593 \\
\hline Anti-muscarinic & Tolterodine & 02299607 \\
\hline Anti-muscarinic & Tospium & 02275066 \\
\hline Anti-androgens & Bicalutamide & 02296063 \\
\hline Anti-androgens & Bicalutamide & 02325985 \\
\hline Anti-androgens & Bicalutamide & 02184478 \\
\hline Anti-androgens & Bicalutamide & 02274337 \\
\hline Anti-androgens & Bicalutamide & 02357216 \\
\hline Anti-androgens & Bicalutamide & 02270226 \\
\hline Anti-androgens & Bicalutamide & 02275589 \\
\hline Anti-androgens & Bicalutamide & 02371324 \\
\hline Anti-androgens & Bicalutamide & 02276089 \\
\hline Anti-androgens & Bicalutamide & 02428709 \\
\hline Anti-androgens & Enzalutamide & 02407329 \\
\hline Anti-androgens & Flutamide & 02059673 \\
\hline Anti-androgens & Nilutamide & 02221861 \\
\hline GnRH agonists & Leuprolide & 02239834 \\
\hline GnRH agonists & Leuprolide & 02230248 \\
\hline GnRH agonists & Leuprolide & 00884502 \\
\hline GnRH agonists & Leuprolide & 02239833 \\
\hline GnRH agonists & Leuprolide & 00836273 \\
\hline GnRH agonists & Goserelin & 02049325 \\
\hline GnRH agonists & Triptorelin & 02240000 \\
\hline GnRH agonists & Triptorelin & 02243856 \\
\hline GnRH agonists & Triptorelin & 02412322 \\
\hline
\end{tabular}




\begin{tabular}{|c|c|c|}
\hline GnRH agonists & Buserelin & 02225166 \\
\hline GnRH agonists & Buserelin & 02225158 \\
\hline GnRH agonists & Histrelin & 02278383 \\
\hline GnRH antagonists & Degarelix & 02337029 \\
\hline GnRH antagonists & Degarelix & 02337037 \\
\hline CYP3A4 inhibitors & Abiraterone & 02371065 \\
\hline Chemotherapy & Docetaxel & 02177099 \\
\hline Chemotherapy & Docetaxel & 02177080 \\
\hline Chemotherapy & Carbazitaxel & 02369524 \\
\hline Chemotherapy & Mitoxantrone & 02244614 \\
\hline Bisphosphonates & Zoledronic acid & 02248296 \\
\hline Steroids & Prednisone & 00598194 \\
\hline Steroids & Prednisone & 00550957 \\
\hline Steroids & Prednisone & 00312770 \\
\hline Steroids & Prednisone & 00021695 \\
\hline Steroids & Prednisone & 00868426 \\
\hline Steroids & Prednisone & 00868434 \\
\hline Steroids & Prednisone & 00868442 \\
\hline Steroids & Prednisone & 00607517 \\
\hline Steroids & Prednisone & 00156876 \\
\hline Steroids & Prednisone & 00021695 \\
\hline Steroids & Prednisone & 00232378 \\
\hline Steroids & Dexamethasone & 02250055 \\
\hline Steroids & Dexamethasone & 02261081 \\
\hline Steroids & Dexamethasone & 00617210 \\
\hline Steroids & Dexamethasone & 00349119 \\
\hline Steroids & Dexamethasone & 00598542 \\
\hline Steroids & Dexamethasone & 00250325 \\
\hline Steroids & Dexamethasone & 00308455 \\
\hline Steroids & Dexamethasone & 02387743 \\
\hline Steroids & Dexamethasone & 00416010 \\
\hline Steroids & Dexamethasone & 00874582 \\
\hline Steroids & Dexamethasone & 00664227 \\
\hline Steroids & Dexamethasone & 01977547 \\
\hline Steroids & Dexamethasone & 02204266 \\
\hline Steroids & Dexamethasone & 02204274 \\
\hline Steroids & Dexamethasone & 02239534 \\
\hline Steroids & Dexamethasone & 00627763 \\
\hline Steroids & Dexamethasone & 02237044 \\
\hline Steroids & Dexamethasone & 02237045 \\
\hline
\end{tabular}




\begin{tabular}{|l|l|l|}
\hline Steroids & Dexamethasone & 02237046 \\
\hline Steroids & Dexamethasone & 02260298 \\
\hline Steroids & Dexamethasone & 02260301 \\
\hline Steroids & Dexamethasone & 01946897 \\
\hline Steroids & Dexamethasone & 01964976 \\
\hline Steroids & Dexamethasone & 01964968 \\
\hline Steroids & Dexamethasone & 01964070 \\
\hline
\end{tabular}

